Article

\title{
Trend Prediction and Decomposed Driving Factors of Carbon Emissions in Jiangsu Province during 2015-2020
}

\author{
Decai Tang ${ }^{1, *}$, Tingyu $\mathrm{Ma}^{2}$, Zhijiang $\mathrm{Li}^{2}$, Jiexin Tang ${ }^{2}$ and Brandon J. Bethel ${ }^{2}$ \\ 1 Institute of Climate Change and Public Policy, Nanjing University of Information Science \& Technology, \\ Nanjing 210044, China \\ 2 School of Economics and Management, Nanjing University of Information Science \& Technology, \\ Nanjing 210044, China; matingyu@nuist.edu.cn (T.M.); 20161262725@nuist.edu.cn (Z.L.); \\ tjx19910922@nuist.edu.cn (J.T.); bjbethel09@gmail.com (B.J.B.) \\ * Correspondence: tangdecai2003@163.com or 002032@nuist.edu.cn; Tel.: +86-25-5869-9857
}

Academic Editor: Marc A. Rosen

Received: 13 June 2016; Accepted: 28 September 2016; Published: 13 October 2016

\begin{abstract}
According to the economic and energy consumption statistics in Jiangsu Province, we combined the $\operatorname{GM}(1,1)$ grey model and polynomial regression to forecast carbon emissions. Historical and projected emissions were decomposed using the Logarithmic Mean Divisia Index (LMDI) approach to assess the relative contribution of different factors to emission variability. The results showed that carbon emissions will continue to increase in Jiangsu province during 2015-2020 period and cumulative carbon emissions will increase by 39.5487 million tons within the forecast period. The growth of gross domestic product (GDP) per capita plays the greatest positive role in driving carbon emission growth. Furthermore, the improvement of energy usage efficiency is the primary factor responsible for reducing carbon emissions. Factors of population, industry structure adjustment and the optimization of fuel mix also help to reduce carbon emissions. Based on the LMDI analysis, we provide some advice for policy-makers in Jiangsu and other provinces in China.
\end{abstract}

Keywords: carbon emissions; GM (1, 1); LMDI decomposition analysis model; trend prediction

\section{Introduction}

Recently, the issue of climate change has been under increasing levels of scrutiny by governments and relevant stakeholders worldwide. The United Nations Intergovernmental Panel on Climate Change (IPCC) has released five assessment reports which analyzed the root causes of climate change and its effect on the planet in the years 1990, 1995, 2001, 2007, with the most recent in 2012. The literature on the subject overwhelmingly suggests that climate change is highly correlated to carbon emissions, and as a result the study of carbon emissions is of unparalleled significance under the background of climate change.

Lying on the eastern coast of mainland China, Jiangsu province (Jiangsu, hereafter), is one of the leading provinces in manufacturing electronics and apparel items. It has a gross domestic product (GDP) of 6.5 trillion yuan ( $\$ 980$ billion USD) in 2015, ranking second nationally. The annual fossil fuel energy consumption of Jiangsu also ranks very highly within the country. As is shown in Figure 1, energy consumption in Jiangsu rapidly increased from 2005-2014, the total amount of energy consumption remains high despite a declining growth rate. Although Jiangsu has advanced manufacturing capabilities and emission reduction technology, due to the construction of high-speed inter-city railways connecting 26 out of 44 counties and cities, it is estimated that the process for urbanization and industrialization of Jiangsu will be further accelerated resulting in increased energy 
demands and economic development-derived carbon emissions. Therefore, conducting a scientific analysis of the future trend of carbon emissions for Jiangsu and devising methods of emission reduction are of great importance.

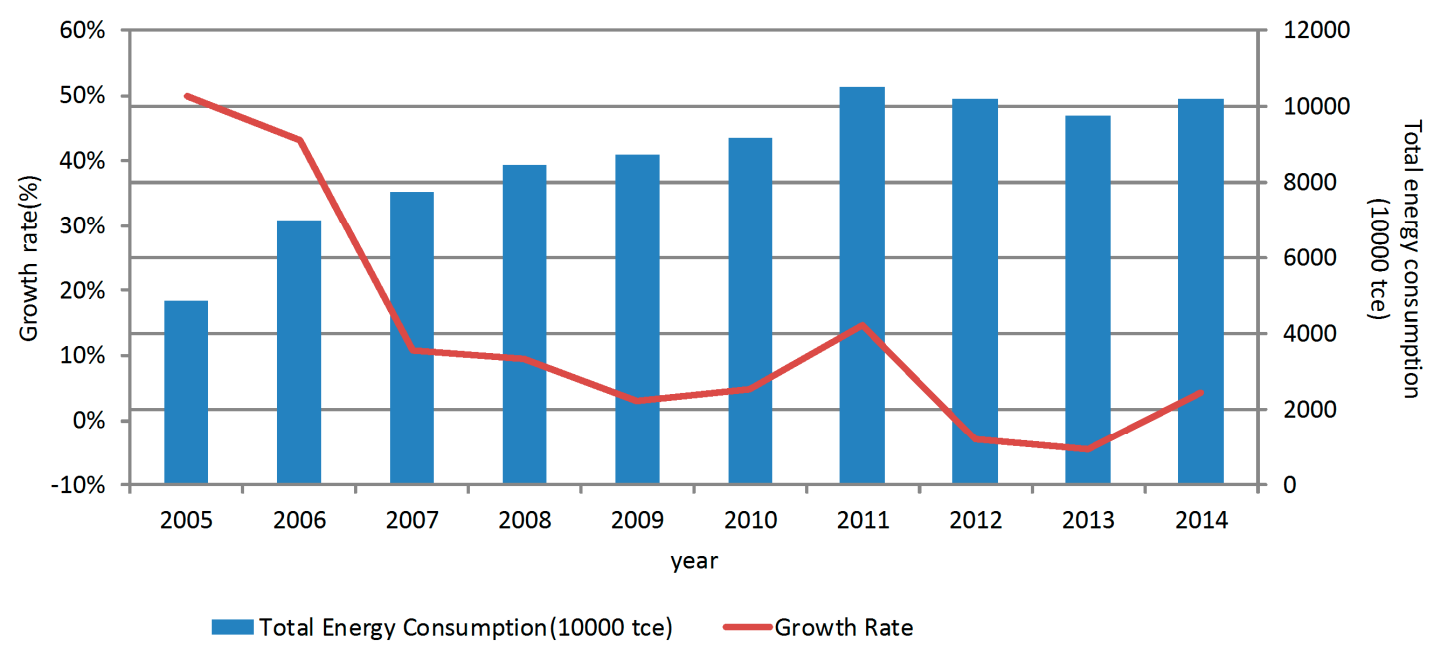

Figure 1. Energy consumption in Jiangsu from 2000-2014.

The relationship between economic growth, energy consumption, and carbon dioxide emissions has been extensively analyzed over the past two decades. Kais [1] provided new empirical evidence to confirm that the Environmental Kuznets Curve (EKC) hypothesis, which was first defined by Simon Kuznets [2], posited an inverted U-shaped curve between economic growth and environmental degradation. Lau [3] indicated that good institutional quality is important in controlling carbon dioxide emissions in the process of economic development. The findings of Gallego-Álvarez [4] showed a reduction in emissions that generates a positive impact on financial performance, contributing to the literature on the relationship between carbon emission reduction and corporate performance.

Estimating and forecasting the amounts of carbon dioxide $\left(\mathrm{CO}_{2}\right)$ emitted into the atmosphere are crucial for planning and analyzing mitigation efforts and for development scenarios of future emissions. Burke [5] investigated carbon dioxide emissions from the combustion of fossil fuels and the manufacture of cement. The works of Tan [6] and Ertugrul [7] provided several extensive studies on the calculation of carbon emissions. A plausible method of computer modeling combining genetic algorithms and a chemical reactor network was developed by Christopher [8] to predict alternative fuel gaseous emissions. Multivariable regression analysis was merged with partial life cycle assessment (LCA) and building information modeling (BIM) for the prediction of environmental degradation within the housing sector [9]. However, forecasting results depended on statistical data, which change rapidly over time. The grey prediction model is an alternative forecasting tool for systems with complex, uncertain and chaotic structures because of their low data requirements to build forecasting models [10]. Initially proposed by Deng [11], the grey model (GM) was used to quantify uncertainty and information insufficiency. Following its proposal, the grey model has been used in various advanced applications. Wang [12] established a small-sample effective rolling GM $(1,1)$ model under eight different datasets to forecast future gas consumption. The metabolic grey model (MGM), metabolic residual-error grey model (MREGM), and the metabolic Markov-residual-error grey model (MMREGM) were proposed by Chen [13] and used to predict the capacity of lithium-ion batteries in relation to discharge cycles throughout their lifetimes. The GM $(1,1)$ model is currently one of the most widely used grey prediction models for predicting carbon emissions [14,15].

The index decomposition analysis (IDA) method has been widely applied to analyze factors influencing carbon emissions. IDAs are mainly divided into Laspeyres index decomposition and Divisia index decomposition analyses [16]. The LMDI method was introduced and developed by Ang [17], 
who concluded it to be the most preferred decomposition analysis due to its robustness, adaptability and transparency in the interpretation of results. Various studies have used LMDI to investigate carbon emissions at regional and national scales [18-20]. Wang [21] found that economic development was the largest factor of increasing carbon dioxide emissions through a modified production-theoretical decomposition analysis approach.

The analysis of carbon emission-related content previously described is applied in various industries and fields of research. The research scope refers to the nationwide level, provincial level, and urban areas. However many of the influencing factors, accounting methods, and emission performance are only targeted towards the past and cannot be used to predict future trends. In the recent National Climate Change Plan (2014-2020) published by the National Development and Reform Commission, the State Council confirmed that China would commit to reduce its $\mathrm{CO}_{2}$ emissions per unit of GDP in 2020 by at least $40 \%-50 \%$ as compared to 2005 , and it was considered as an indicator of economic development in long-term planning. In this paper, the decomposition analysis for carbon emission factors is focused on future economic development and the energy consumption trend of the province of Jiangsu. In order to meet the target of long-term emission reductions, all relevant statistical data are conducted using a grey prediction model and a method of LMDI decomposition has been applied to future emissions projections, which is aimed at describing future directions of emission reduction for Jiangsu and providing advice on the formulation of emission reduction policies for Jiangsu and other provinces with similar economic and environmental circumstances.

The rest of this paper is organized as follows: Section 2 presents the methodology and data; forecasting and decomposition results are put forward in Section 3; Section 4 provides a discussion of the results; and Section 5 gives the conclusion and puts forward advice based on the results of the analysis.

\section{Methodology and Data}

\subsection{Data Source}

The data used in the following study includes population, energy consumption data, and economic data, etc., which were obtained from the Regional Statistical Yearbook [22-51].

Population and economic data were collected from the Jiangsu Statistical Yearbook 2001-2015 [22-35]. Energy consumption data for each sector were extracted from the China Energy Statistical Yearbook 2001-2015 [35-51]. Energy consumption of Jiangsu was divided into three parts: primary, secondary, and tertiary industries. The types of fuels consumed by three industries included eight typical kinds: raw coal, cleaned coal, coke, gasoline, diesel, fuel oil, liquefied petroleum gas, and natural gas. For ease of calculations, we categorize these eight types of energy sources as coal, petroleum, and natural gas; and $\mathrm{CO}_{2}$ emissions are calculated with the three aggregated fuels. Corresponding to the types of energy sources, this paper takes the mean values of raw coal, cleaned coal, and coke's carbon emission coefficients as coal's carbon emission coefficient, and the mean values of gasoline, diesel, fuel oil, and liquefied petroleum gas' emission coefficients as oil's carbon emission coefficient. Due to the small variation in the coal and petroleum energy source's inter-source carbon emission coefficients, and the addition of this paper's main study of the evolution of emission increases and structural composition, the aggregation essentially will not have an impact on the final conclusion. The $\mathrm{CO}_{2}$ emission factors for the eight types of fuels and three reclassified types are summarized in Table 1.

$\mathrm{CO}_{2}$ emissions are calculated by the following equation:

$$
C=\sum_{i} e_{i} \times f_{i} \times k_{i}
$$

where $e_{i}$ denotes the consumption of fuel $i$ (unit: cubic meter for liquefied petroleum gas, and natural gas; $\mathrm{kg}$ for other fuels); $f_{i}$ is the standard coal coefficient used to convert the different types of energy to standard coal equivalents (SCE), which is derived from the General Principles of Comprehensive 
Energy Consumption Calculation (unit: $\mathrm{kgce} /$ cubic meter; $\mathrm{kgce} / \mathrm{kg}$ ); $k_{i}$ is the $\mathrm{CO}_{2}$ emission factor for different types of fuels from the Guidelines on Provincial Greenhouse Gas Inventories.

Table 1. Various fuel $\mathrm{CO}_{2}$ emission factors (unit: $\mathrm{kg} / \mathrm{kgce}$ ).

\begin{tabular}{cccc}
\hline Original Fuels & Factors & Aggregated Fuels & Factors \\
\hline Raw Coal & 0.7559 & & \\
Cleaned Coal & 0.7559 & Coal & 0.7889 \\
Coke & 0.8550 & & \\
\hline Gasoline & 0.5538 & & 0.56715 \\
Diesel & 0.5921 & Oil & \\
Fuel Oil & 0.6185 & & 0.4483 \\
\hline Liquefied Petroleum Gas & 0.5042 & Natural Gas & \\
\hline Natural Gas & 0.4483 & &
\end{tabular}

\section{2. $G M(1,1)$ Model}

The algorithm of the GM $(1,1)$ grey prediction model can be summarized as follows:

Step 1: the non-negative time-sequence data $X^{(0)}$ is expressed as:

$$
X^{(0)}=\left\{x^{(0)}(1), x^{(0)}(2), \ldots, x^{(0)}(n)\right\}
$$

where $n \geq 3$.

Step 2: take accumulated generating operation (AGO) on $X^{(0)}$ to weaken modulation tendencies:

$$
X^{(1)}=\left\{x^{(1)}(1), x^{(1)}(2), \ldots, x^{(1)}(n)\right\}
$$

where $x^{(1)}(n)=\sum_{k=1}^{n} x^{(0)}(k)$.

Step 3: the basic form of GM $(1,1)$ is described by the following equation:

$$
X^{(0)}(t)+a \cdot X^{(1)}(t)=u
$$

where $t$ denotes the independent variables in the system, $a$ represents the developed coefficient, and $u$ is the grey controlled variable. The model requires solutions for $a$ and $u$.

Step 4: by using the ordinary least-square method, coefficient $\widehat{a}$ becomes:

$$
\widehat{a}=\left[\begin{array}{l}
a \\
u
\end{array}\right]=\left(B^{T} B\right)^{-1} B^{T} Y_{n}
$$

where:

$$
B=\left[\begin{array}{llll}
-\frac{1}{2}\left(x^{(1)}(1)+x^{(1)}(2)\right) & 1 & \cdots & 1 \\
-\frac{1}{2}\left(x^{(1)}(2)+x^{(1)}(3)\right) & 1 & \cdots & 1 \\
\vdots & 1 & \cdots & 1 \\
-\frac{1}{2}\left(x^{(1)}(n-1)+x^{(1)}(n)\right) & 1 & \cdots & 1
\end{array}\right], \text { and } Y_{n}=\left[x_{1}^{(0)}(2), x_{1}^{(0)}(3), \cdots, x_{1}^{(0)}(n)\right]^{T}
$$

Step 5: according to the estimated coefficients $a$ and $u$, the response equation can be obtained:

$$
\widehat{x}^{(1)}(t+1)=\left(x^{(0)}(1)-\frac{u}{a}\right) e^{-a t}+\frac{u}{a}
$$


Step 6: by performing inverse accumulated generating operation (IAGO) on $\widehat{x}^{(1)}$, the prediction value is produced:

or:

$$
\widehat{x}^{(0)}(t+1)=-a \cdot\left(x^{(0)}(1)-\frac{u}{a}\right) e^{-a t}
$$

$$
\widehat{x}^{(0)}(t+1)=\widehat{x}^{(1)}(t+1)-\widehat{x}^{(1)}(t)
$$

To demonstrate the reliability of the GM $(1,1)$ model, the posterior variance test is used to discuss the results of fitting and prediction. Criteria of the posterior variance test include the indicators, posterior variance ratio $C$, and small error probability $P$.

The posterior variance ratio is defined as follows:

$$
\mathrm{C}=\frac{S_{2}}{S_{1}}=\sqrt{\frac{S_{2}^{2}}{S_{1}^{2}}}
$$

where $S_{2}{ }^{2}=\frac{1}{m-1} \sum_{t=1}^{m-1}\left(\varepsilon^{(0)}(t)-\bar{\varepsilon}^{(0)}(t)\right)^{2}$, and $S_{1}{ }^{2}=\frac{1}{m-1} \sum_{t=1}^{m}\left(x^{(0)}(t)-\bar{x}^{(0)}(t)\right)^{2}$.

$\varepsilon^{(0)}(t)$ represents the residual between the predicted value $\widehat{x}^{(0)}(t)$ and the actual value $x^{(0)}(t)$ at time $t$.

Small error probability $\mathrm{P}$ is expressed as $\mathrm{P}=\left\{\left|\mathcal{\varepsilon}^{(0)}(t)-\bar{\varepsilon}^{(0)}(t)\right|<0.6745 S_{1}\right\}$. The range of indicator values $C$ and $P$ is such that: $C>0,0 \leq P \leq 1$, where $P>0.95$ and $C<0.35$ indicates a highly accurate forecast, $\mathrm{P}>0.60$ and $\mathrm{C}<0.80$ indicates a reasonable forecast, and $\mathrm{P}<0.60$ and $\mathrm{C}>0.80$ indicates an unreasonable range.

\subsection{Polynomial Regression Analysis}

Polynomial regression analysis is a powerful statistical tool for estimating relationships between variables, which has many applications in different areas, such as engineering, the environmental sciences, finance, and economics. It can be summarized by the following steps:

(1) Determine the number of polynomials by observing the changing trend of the actual data.

(2) Transform the general polynomial $y=a_{0}+a_{1} x+a_{2} x^{2}+\cdots+a_{m} x^{m}$ into a linear function $y=a_{0}+a_{1} z_{1}+a_{2} z_{2}+\cdots+a_{m} z_{m}$, where $z_{1}=x, z_{1}=x^{2}, \cdots, z_{m}=x^{m}$.

(3) Estimate the parameters $a_{0}, a_{1}, a_{2}, \cdots, a_{m}$ by using the ordinary least-square method.

(4) Calculate the predicted values with the estimated multivariate linear function.

\subsection{LMDI Decomposition Model}

The LMDI decomposition approach is widely used in studies of environment and energy problems. A practical guide to Log-Mean Divisia Index Method I (LMDI-I ) is given by Ang [17]. Changes in $\mathrm{CO}_{2}$ emissions from industry may be studied by quantifying the contributions the variability of six different factors: population, GDP (PPP) per capita, industrial activity mix, energy intensity, fuel mix, and $\mathrm{CO}_{2}$ emission factors. The subcategories of the aggregate are the industrial sectors and fuel types. The decomposition analysis problem can be formulated either additively or multiplicatively. In multiplicative decomposition, we decompose the $\mathrm{CO}_{2}$ emissions changes into the following factors:

$$
C=\sum_{i=1}^{m} \sum_{j=1}^{n} \frac{C_{i j}}{E_{i j}} \times \frac{E_{i j}}{E_{i}} \times \frac{E_{i}}{G_{i}} \times \frac{G_{i}}{G} \times \frac{G}{R} \times R=\sum_{i=1}^{m} \sum_{j=1}^{n} k_{i j} \times n_{i j} \times e_{i} \times s_{i} \times w \times r
$$

Variable definitions are summarized in Table 2. 
Table 2. Definitions of variables.

\begin{tabular}{ccc}
\hline Variables & Definitions & Unit \\
\hline$R$ & Population & $1.0 \times 10^{4}$ persons \\
$G$ & GDP & $1.0 \times 10^{8}$ yuan \\
$G_{i}$ & GDP of industrial sectors & $1.0 \times 10^{8}$ yuan \\
$E_{i}$ & Gross energy consumption of industrial sectors & $1.0 \times 10^{4}$ tce \\
$E_{i j}$ & Consumption of fuel $j$ in industrial sector $i$ & $1.0 \times 10^{4}$ tce \\
$C_{i j}$ & $\mathrm{CO}_{2}$ emissions arising from fuel $j$ in industrial sector $i$ & $1.0 \times 10^{4}$ tons \\
$r$ & Population size & $1.0 \times 10^{4}$ persons \\
$w$ & GDP per capita & yuan $/$ person \\
$s_{i}$ & Share of GDP of industrial sector $i$ & Percentage point \\
$e_{i}$ & Energy intensity in industrial sector $i$ & tce $/ 1.0 \times 10^{4}$ yuan \\
$n_{i j}$ & Fuel mix (share of consumption of fuel $j$ in gross Energy consumption in industrial sector $i)$ & Percentage point \\
$k_{i j}$ & $\mathrm{CO}_{2}$ emission coefficient: $\mathrm{CO}_{2}$ emission per unit of Fuel $j$ in industrial sector $i$ & $1.0 \times 10^{4}$ tons \\
\hline \multicolumn{2}{c}{}
\end{tabular}

In additive decomposition, we decompose the increased carbon emissions:

$$
\Delta C=\Delta C_{r}+\Delta C_{w}+\Delta C_{s}+\Delta C_{e}+\Delta C_{n}+\Delta C_{k}
$$

Similar to some related studies, because $\mathrm{CO}_{2}$ emission coefficients of various energy sources are all assumed to be fixed when calculating $\mathrm{CO}_{2}$ emissions, the term $\Delta C_{k}$ in the equation does not contribute to $\mathrm{CO}_{2}$ emission variability and has a value of zero. Hence, the final drivers of $\mathrm{CO}_{2}$ emission variability are decomposed into five corresponding factors:

$$
\Delta C=\Delta C_{r}+\Delta C_{w}+\Delta C_{s}+\Delta C_{e}+\Delta C_{n}
$$

where $\Delta C_{r}$ denotes the $\mathrm{CO}_{2}$ increase or decrease increments as caused by a change in population; $\Delta C_{w}$ is the increment of $\mathrm{CO}_{2}$ emissions caused by change of GDP per capita; $\Delta C_{s}$ is the increment of $\mathrm{CO}_{2}$ emissions caused by changes in industrial structure, which is represented by a share of GDP in the industrial sector $i ; \Delta C_{e}$ is the increment of $\mathrm{CO}_{2}$ emissions caused by changes in energy intensity; and $\Delta C_{n}$ is the increment of $\mathrm{CO}_{2}$ emissions caused by change in the proportion of energy consumption. The LMDI formulae are summarized in Table 3 where $\mathrm{m}$ represents the types of industry, $n$ represents the types of energy, and $t$ represents the year.

\begin{tabular}{|c|c|}
\hline \multicolumn{2}{|c|}{ Additive Decomposition } \\
\hline Change Scheme & LMDI Formulae \\
\hline \multirow{5}{*}{$\Delta C=\Delta C_{r}+\Delta C_{w}+\Delta C_{s}+\Delta C_{e}+\Delta C_{n}$} & $\Delta C_{r}=\sum_{i=1}^{m} \sum_{j=1}^{n}\left(\frac{C_{i j}^{t+1}-C_{i j}^{t}}{\ln C_{i j}^{t+1}-\ln C_{i j}^{t}}\right) \times \ln \left(\frac{r(t+1)}{r(t)}\right)$ \\
\hline & $\Delta C_{w}=\sum_{i=1}^{m} \sum_{j=1}^{n}\left(\frac{C_{i j}^{t+1}-C_{i j}^{t}}{\ln C_{i j}^{t+1}-\ln C_{i j}^{t}}\right) \times \ln \left(\frac{w(t+1)}{w(t)}\right)$ \\
\hline & $\Delta C_{s}=\sum_{i=1}^{m} \sum_{j=1}^{n}\left(\frac{C_{i j}^{t+1}-C_{i j}^{t}}{\ln C_{i j}^{t+1}-\ln C_{i j}^{t}}\right) \times \ln \left(\frac{s_{i}(t+1)}{s_{i}(t)}\right)$ \\
\hline & $\Delta C_{e}=\sum_{i=1}^{m} \sum_{j=1}^{n}\left(\frac{C_{i j}^{t+1}-C_{i j}^{t}}{\ln C_{i j}^{t+1}-\ln C_{i j}^{t}}\right) \times \ln \left(\frac{e_{i}(t+1)}{e_{i}(t)}\right)$ \\
\hline & $\Delta C_{n}=\sum_{i=1}^{m} \sum_{j=1}^{n}\left(\frac{C_{i j}^{t+1}-C_{i j}^{t}}{\ln C_{i j}^{t+1}-\ln C_{i j}^{t}}\right) \times \ln \left(\frac{n_{i j}(t+1)}{n_{i j}(t)}\right)$ \\
\hline
\end{tabular}

Table 3. The LMDI formulae.

\section{Results}

\subsection{Forecasting Results}

In the primary industry, natural gas consumption remained zero over the past 15 years, and it is less likely to be consumed on a large scale in the future. As a result, it is assumed that the consumption 
is still zero in the forecast period. To better evaluate the performance of the GM $(1,1)$ model, indicator values $C$ and $P$ are calculated and the model evaluation results are given in Table 4 .

Table 4. GM $(1,1)$ model evaluation results.

\begin{tabular}{ccc}
\hline Prediction Terms & C Value & P Value \\
\hline Population & 0.1536 & 1.0000 \\
Primary Industry GDP & 0.1351 & 1.0000 \\
Secondary Industry GDP & 0.1511 & 1.0000 \\
Tertiary Industry GDP & 0.0795 & 1.0000 \\
Primary Industry Coal Consumption & 0.3891 & 1.0000 \\
Primary Industry Oil Consumption & 0.4019 & 0.9333 \\
Primary Industry Natural Gas Consumption & model is not suitable for prediction \\
Secondary Industry Coal Consumption & 0.4185 & 1.0000 \\
Secondary Industry Oil Consumption & 0.3208 & 0.8889 \\
Secondary Industry Natural Gas Consumption & 1.4430 & 0.3333 \\
Tertiary Industry Coal Consumption & 0.6940 & 0.7333 \\
Tertiary Industry Oil Consumption & 0.2309 & 1.0000 \\
Tertiary Industry Natural Gas Consumption & 1.4464 & 0.3333 \\
\hline
\end{tabular}

In accordance with the optimum range of indicator values $C$ and $P$, as previously mentioned, most of the model produced very good estimates except for secondary industry natural gas consumption and tertiary industry natural gas consumption. Those two terms were predicted by the polynomial regression model. Results are shown in Table 5.

Table 5. Evaluation results of polynomial regression analysis.

\begin{tabular}{ccc}
\hline Prediction Terms & Prediction Model & Adjusted $\mathbf{R}^{2}$ \\
\hline Secondary Industry Natural Gas Consumption & $\mathrm{Y}=-0.202 \mathrm{X}^{3}+8.639 \mathrm{X}^{2}-32.021 \mathrm{X}+27.044$ & $\mathrm{R}^{2}=0.9906$ \\
Tertiary Industry Natural Gas Consumption & $\mathrm{Y}=-0.22 \mathrm{X}^{3}+1.387 \mathrm{X}^{2}-9.005 \mathrm{X}+11.305$ & $\mathrm{R}^{2}=0.9054$ \\
\hline
\end{tabular}

The prediction results of the above factors are shown in Table 6.

Table 6. Prediction results.

\begin{tabular}{cccccccc}
\hline Prediction Terms & Unit & $\mathbf{2 0 1 5}$ & $\mathbf{2 0 1 6}$ & $\mathbf{2 0 1 7}$ & $\mathbf{2 0 1 8}$ & $\mathbf{2 0 1 9}$ & $\mathbf{2 0 2 0}$ \\
\hline Population & $/ 10,000$ persons & 8079.24 & 8130.83 & 8182.75 & 8234.99 & 8287.58 & 8340.50 \\
Primary Industry GDP & $1.0 \times 10^{8} \mathrm{RMB}$ & 4301.58 & 4773.69 & 5297.61 & 5879.04 & 6524.27 & 7240.33 \\
Secondary Industry GDP & $1.0 \times 10^{8} \mathrm{RMB}$ & $39,486.8$ & $44,824.1$ & $50,882.8$ & $57,760.5$ & $65,567.9$ & $74,430.5$ \\
Tertiary Industry GDP & $1.0 \times 10^{8} \mathrm{RMB}$ & $39,193.4$ & $46,392.8$ & $54,914.8$ & $65,502.2$ & $76,492.5$ & $91,076.2$ \\
Primary Industry Coal Consumption & $1.0 \times 10^{4}$ tce & 35.10 & 34.09 & 33.11 & 32.16 & 31.23 & 30.33 \\
Primary Industry Oil Consumption & $1.0 \times 10^{4}$ tce & 358.61 & 383.63 & 410.41 & 439.05 & 469.69 & 502.47 \\
Primary Industry Natural Gas Consumption & $1.0 \times 10^{4}$ tce & 0 & 0 & 0 & 0 & 0 & 0 \\
Secondary Industry Coal Consumption & $1.0 \times 10^{4}$ tce & 8865.8 & 9563.3 & $10,315.5$ & $11,127.0$ & $12,002.3$ & $12,946.5$ \\
Secondary Industry Oil Consumption & $1.0 \times 10^{4}$ tce & 371.87 & 348.84 & 327.23 & 306.96 & 287.95 & 270.11 \\
Secondary Industry Natural Gas Consumption & $1.0 \times 10^{4}$ tce & 896.88 & 984.51 & 1068.77 & 1148.44 & 1222.29 & 1289.13 \\
Tertiary Industry Coal Consumption & $1.0 \times 10^{4}$ tce & 21.32 & 20.36 & 19.45 & 18.58 & 17.75 & 16.96 \\
Tertiary Industry Oil Consumption & $1.0 \times 10^{4}$ tce & 1908.72 & 2068.22 & 2241.04 & 2428.31 & 2631.23 & 2851.11 \\
Tertiary Industry Natural Gas Consumption & $1.0 \times 10^{4}$ tce & 132.05 & 150.82 & 170.12 & 189.81 & 209.76 & 229.85 \\
\hline
\end{tabular}

\subsection{LMDI Decomposition Results}

Table 7 shows $\mathrm{CO}_{2}$ emissions and the contribution of the various factors from 2000-2014.

Table 7 reflects the decomposition of increased carbon emissions. The combined effect on carbon emissions was 47.2428 million tons between the years of 2000-2014. Between the years 2000-2014, population, changes in industrial structure, economic structure, energy intensity, and energy structure contributed 3.8604 million tons, 96.7029 million tons, -7.1764 million tons, -45.2076 million tons, and 
-936.5 thousand tons to carbon emissions, respectively. Negative values of total contribution indicate reduced carbon emissions as compared to the previous year. Except for years 2000, 2004, 2011, and 2012, carbon emissions in other years continued to rise. Based on the LMDI decomposition approach, we can identify the extent to which the total changes of these influencing factors contributed to the total growth of carbon emissions. As is shown in Figure 2, among those factors, economic structure played the greatest positive role in increasing carbon emissions, and energy intensity is the key factor for reducing carbon emissions. The remaining three factors, population, industrial structure, and fuel mix, have limited effects.

Table 7. Decomposition of the $\mathrm{CO}_{2}$ emissions from 2000-2014 (unit: 10,000 tons).

\begin{tabular}{ccccccc}
\hline Year & Population & $\begin{array}{c}\text { Economy } \\
\text { Structure }\end{array}$ & $\begin{array}{c}\text { Industry } \\
\text { Structure }\end{array}$ & $\begin{array}{c}\text { Energy } \\
\text { Intensity }\end{array}$ & $\begin{array}{c}\text { Fuel } \\
\text { Mix }\end{array}$ & $\begin{array}{c}\text { Total } \\
\text { Contribution }\end{array}$ \\
\hline $2001-2000$ & 10.11 & 228.10 & 0.52 & -326.77 & -4.00 & -92.04 \\
$2002-2001$ & 15.17 & 258.33 & 23.93 & -181.72 & -6.65 & 109.06 \\
$2003-2002$ & 17.99 & 390.85 & 43.72 & -190.45 & -12.64 & 249.46 \\
$2004-2003$ & 27.73 & 567.95 & 56.64 & 370.05 & 21.67 & 1044.04 \\
$2005-2004$ & 30.68 & 732.04 & 11.69 & -1045.57 & -29.47 & -300.64 \\
$2006-2005$ & 36.84 & 613.55 & -8.00 & 896.50 & 60.10 & 1598.97 \\
$2007-2006$ & 47.14 & 917.56 & -59.39 & -353.43 & -6.93 & 544.95 \\
$2008-2007$ & 29.92 & 997.84 & -58.91 & -437.24 & -18.05 & 513.55 \\
$2009-2008$ & 38.33 & 625.59 & -79.54 & -404.40 & 8.46 & 188.43 \\
$2010-2009$ & 49.02 & 1149.17 & -121.51 & -789.77 & -3.12 & 283.79 \\
$2011-2010$ & 26.68 & 1188.22 & -112.33 & -142.57 & 4.15 & 964.15 \\
$2012-2011$ & 20.11 & 700.65 & -116.01 & -824.69 & -53.40 & -273.35 \\
$2013-2012$ & 17.75 & 704.92 & -162.01 & -865.38 & -37.55 & -342.27 \\
$2014-2013$ & 18.58 & 595.54 & -136.42 & -225.31 & -16.22 & 236.16 \\
Total & 386.04 & 9670.29 & -717.64 & -4520.76 & -93.65 & 4724.28 \\
\hline
\end{tabular}

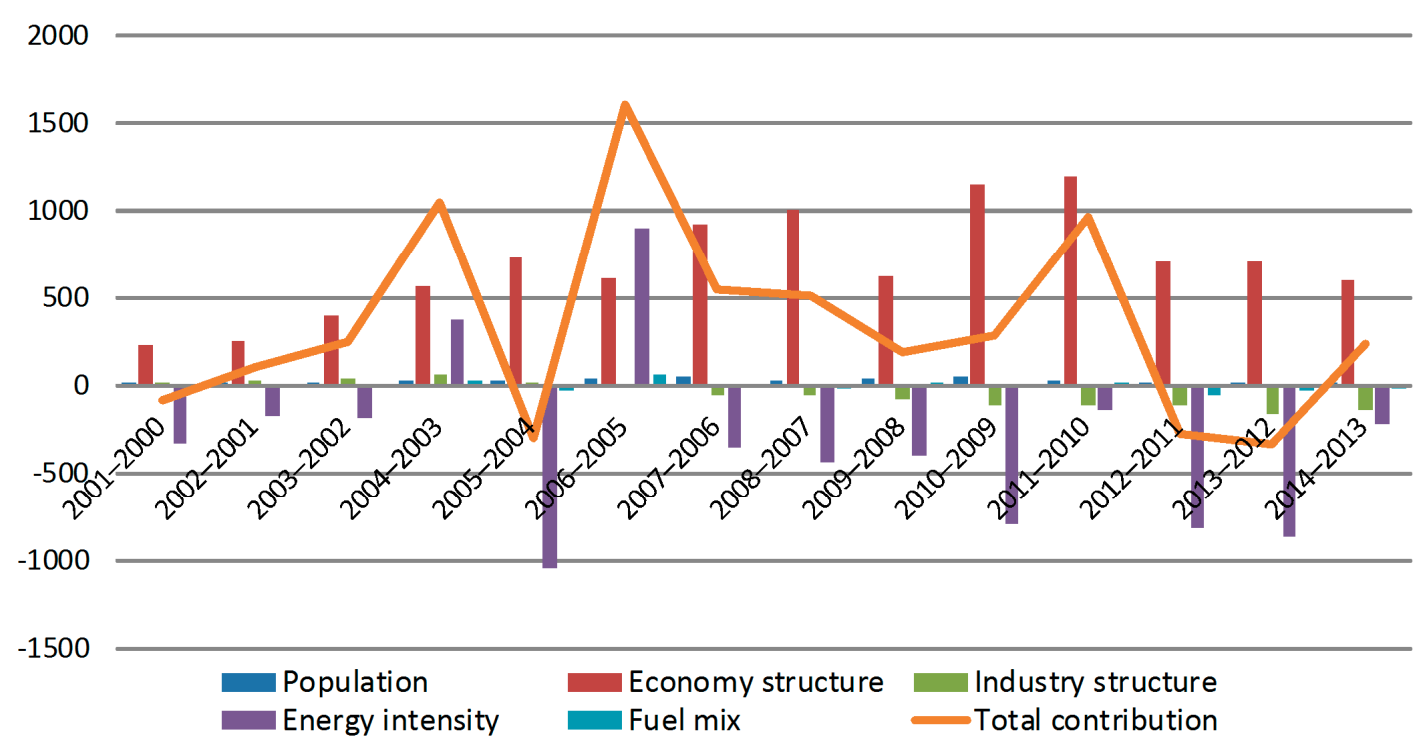

Figure 2. Decomposition of $\mathrm{CO}_{2}$ emissions from 2000-2014 (unit: 10,000 tons).

According to the decomposition results in Table 8, cumulative carbon emissions will increase by 39.5487 million tons during the forecast period. Economic growth will still be the main driving force and variability in energy intensity will be the main constraint in the growth of carbon emissions. 
Table 8. Decomposition of $\mathrm{CO}_{2}$ emissions from 2015-2020 (unit: 10,000 tons).

\begin{tabular}{ccccccc}
\hline Year & Population & $\begin{array}{c}\text { Economy } \\
\text { Structure }\end{array}$ & $\begin{array}{c}\text { Industry } \\
\text { Structure }\end{array}$ & $\begin{array}{c}\text { Energy } \\
\text { Intensity }\end{array}$ & $\begin{array}{c}\text { Fuel } \\
\text { Mix }\end{array}$ & $\begin{array}{c}\text { Total } \\
\text { Contribution }\end{array}$ \\
\hline $2016-2015$ & 59.69 & 1306.05 & -131.46 & -545.84 & -16.54 & 671.90 \\
$2017-2016$ & 64.26 & 1410.97 & -146.14 & -591.58 & -10.11 & 727.40 \\
$2018-2017$ & 69.15 & 1524.03 & -162.27 & -641.26 & -2.87 & 786.79 \\
$2019-2018$ & 74.41 & 1645.81 & -179.97 & -695.01 & 5.12 & 850.36 \\
$2020-2019$ & 80.05 & 1776.93 & -199.38 & -752.97 & 13.79 & 918.43 \\
Total & 347.57 & 7663.80 & -819.23 & -3226.66 & -10.61 & 3954.87 \\
\hline
\end{tabular}

\section{Discussion}

\subsection{Economic Factors Analysis}

As is easily seen in Table 7, throughout the years 2000-2010, the effect of economic growth on rising carbon emissions in Jiangsu Province is positive and has a rising trend. Since 2011, the contribution of economy structure has experienced a declining trend in increasing $\mathrm{CO}_{2}$ emissions. This result conforms with the fact that the economic growth slowed down during China's 'Twelfth Five Year Plan' period (2011-2015), as compared to the 'Eleventh Five Year Plan', where the economy underwent a significant surge. Due to the global economic depression, China's domestic economic development entered a new state of normalcy. In the complex global political and economic environment, Jiangsu actively promoted the optimization and upgrading of industrial structure. The province has maintained a stable rate of rapid growth under the relatively large stress of economic depression. Following the optimization of the industrial structure and the recovery of the global economy it is predicted that, within the estimation period, the contribution of Jiangsu's economic structure will continue an upwards trend. As seen in Table 8, the overall increase in carbon emission caused by economic factors will be 76.6380 million tons, which then leads to the conclusion that, in curbing carbon emissions, a path of reducing economic growth must be taken. Though Jiangsu has made great contributions to the China's economic development over the years, and the regional GDP is ranking at the forefront, there exists a great disparity between residential living standards and civil construction. In the near future, the task of developing the economic situation and improving residential living standards will continue to exist, while the economic growth speed of Jiangsu will not undergo a significant decrease. Thus, it can be seen that, with respect to Jiangsu, it is not enough to only rely on the control of economic growth for emission reduction; what is more important is to cooperate with other emission reduction-related affairs.

\subsection{Energy Intensity Factor Analysis}

Energy intensity is the ratio of energy consumption divided by GDP, which shows energy usage efficiency. As Table 7 shows, the energy intensity has little contribution to carbon emission increase within the period of 2000-2014. The result reveals that the energy efficiency has improved significantly and has contributed greatly to reducing carbon emissions. As shown in Figure 3, the three major industries' contributions to the energy intensity are essentially negative; moreover, the largest negative contribution came from the secondary industry. The contribution to energy intensity from the primary industry remained constant, and the value of negative contribution every year is minor. The reason for this might be that the size of the primary industry is very small and, by taking this into consideration, the future devotion to the improvement of the secondary industry energy intensity should be given.

With the vigorous promotion of energy-conserving and emission-reducing equipment and technology, it is estimated that the energy efficiency for Jiangsu will continually increase as energy intensity decreases. Macroeconomic control that is mainly focused on energy conservation and emission reduction policies will be strengthened. The effect from earlier emission reduction policies will gradually bear fruit and, as shown in Table 8, during the time of forecasting data, energy intensity is still a main factor in curbing carbon emission growth. 


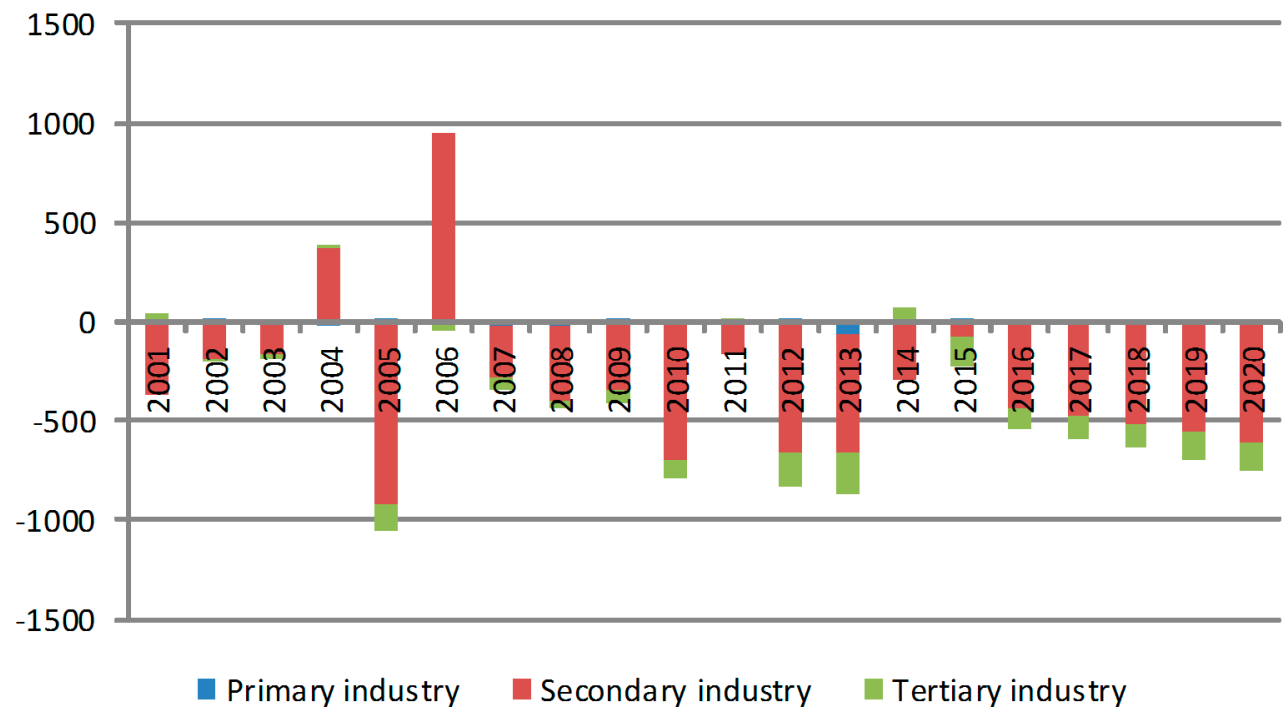

Figure 3. Incremental effects of carbon emission from energy intensity contributions.

\subsection{Industrial Structure Factor Analysis}

According to the value of the contribution from the industrial structure on carbon emissions varying in Table 7 above, the historical data can be divided into two stages:

(1) Covering a period of 2000-2005, the effect on carbon emission amount from the industrial structure fluctuates and the absolute value is small. Therefore, the change of the industrial structure has a limited restricting effect on carbon emissions.

(2) During the period of 2006-2014, the absolute value of contributions from the industrial structure on emission reduction has increased, which obviously shows trend of carbon emission reduction.

During the study estimation period, adjustments to the industrial structure had an obvious increasingly restrictive effect on carbon emission growth. As seen from Table 8, the absolute value of the industrial structure's yearly contribution rose. From Table 9 it can be shown that, in the future, the secondary industry in Jiangsu will play an important role in emission reductions. The tertiary industry will increase its amount of the carbon emissions. Calculations demonstrate that, during the period of estimation, total input averages of the secondary and tertiary industries were $45 \%$ and $50 \%$, respectively. Furthermore, the average annual contribution of energy intensity on carbon emissions for secondary and tertiary industries, respectively, are -1.8383 million tons and 313,800 tons. Therefore, the slightly lower proportion of the secondary industry output will result in good emission reductions. Though the proportion of tertiary industry increased every year, there were limited effects on carbon emissions. In the future, Jiangsu will continue the trend of transforming itself from higher proportions of secondary industries to tertiary ones, and this will have a great effect on emission reductions.

Table 9. Incremental effects of industrial structure from 2015-2020 (unit: 10,000 tons).

\begin{tabular}{ccccc}
\hline Year & Primary Industry & Secondary Industry & Tertiary Industry & Total Effects \\
\hline $2016-2015$ & -9.86 & -149.47 & 27.87 & -131.46 \\
$2017-2016$ & -10.57 & -165.12 & 29.55 & -146.14 \\
$2018-2017$ & -11.33 & -182.24 & 31.30 & -162.27 \\
$2019-2018$ & -12.15 & -200.95 & 33.13 & -179.97 \\
$2020-2019$ & -13.05 & -221.37 & 35.04 & -199.38 \\
Average & -11.39 & -183.83 & 31.38 & -163.85 \\
\hline
\end{tabular}




\subsection{Energy Structure Factor Analysis}

As seen from historical data, there is a slight effect of the energy consumption structure on carbon emissions which then leads to the proposition that energy structure composition has a relatively small influence on carbon emissions. Generally speaking, adjusting the energy structure would have an unstable and limited effect on carbon emission reductions. Starting in 2003, it can be shown that the energy structure had made positive contributions to carbon emissions. As Figure 4 illustrates, perhaps there was a decline in the ratio of petroleum consumption, which was accompanied by a gradual increase in the ratio of natural gas consumption. Lending credence to this hypothesis, the ratio of petroleum consumption decreased from 38\% in 2003 to $24 \%$ in 2014 and, also as a result of the implementation of a west-east transmission of natural gas policy, the ratio of natural gas consumption increased to $9 \%$ from $2.31 \%$ in 2005 . During the estimation period, adjustments of energy structures does not have an obvious effect on the restriction of increasing carbon emission growth; however, this effect is gradually disappearing. The reason for this is that the proportion of coal consumption was not significantly lowered. As is shown in Table 6, estimation data of the three major industries (primary, secondary, and tertiary) shows that the demand for coal grows daily. When energy consumption categories in Jiangsu are mostly comprised of coal, petroleum, and natural gas, small changes in the energy structure does not have a great effect on carbon emission reduction. With regard to energy sources, future strategies of emission reduction in this province must increasing rely on energy utilization efficiency.

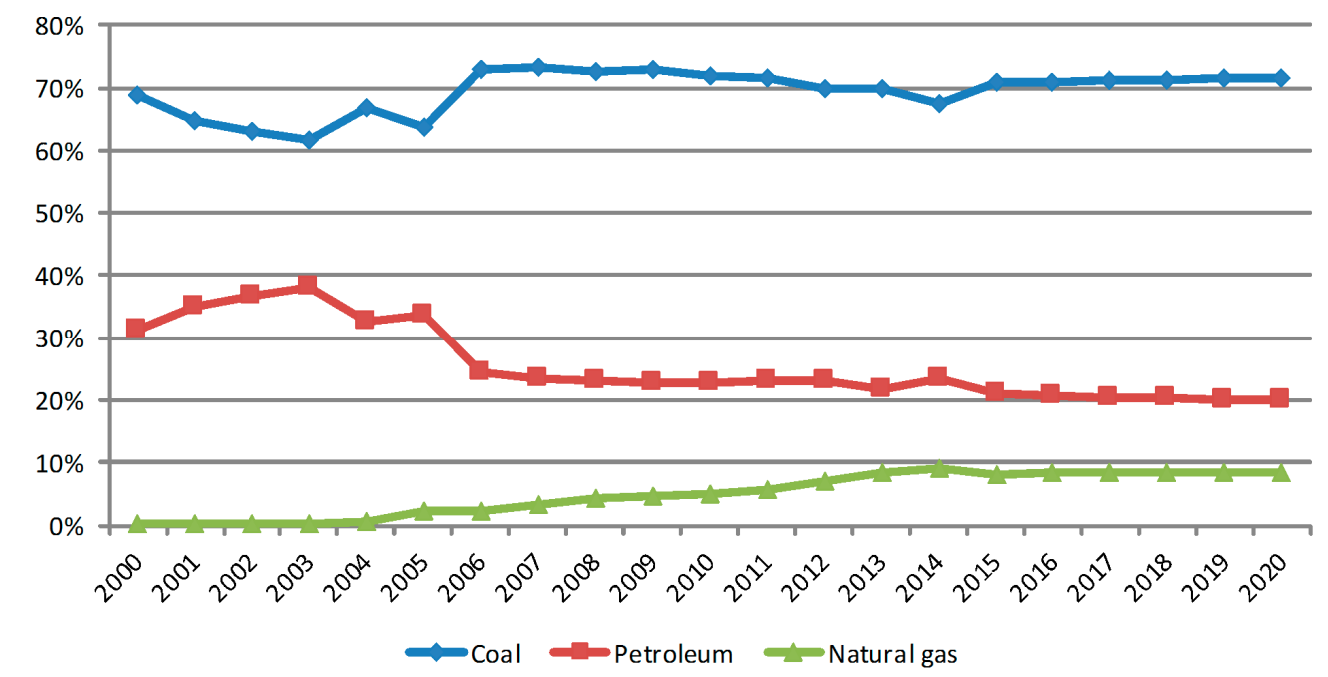

Figure 4. Energy consumption structure.

\subsection{Demographic Factors Analysis}

As seen from historical data, the effect on carbon emission from demographic factors is stable, and changes in numerical values are not obvious. In recent years, Jiangsu was faced with the problem of rapid increases in population size and, for some cities, floating populations, i.e., the part of the population which resides in an area for a certain amount of time and for an array of reasons, but are not generally considered during an official census exercise, have exceeded the actual long-term/permanent resident population. Urbanization has consumed a lot of building materials and energy while, at the same time, people's consumption habits have also significantly changed. All of these factors will contribute to increasing levels of energy consumption and, correspondingly, carbon emissions. According to model decomposition, it was found that population growth will lead to more carbon emissions during the period of 2015-2020. The absolute value of carbon emission caused by demographic factors is not large, but it ranks second only to economic factors. As Table 7 shows, the effect on carbon emissions from demographic factors is expected to be up to 3.4757 million tons from 2015-2020. 


\section{Conclusions and Suggestions}

\subsection{Conclusions}

In this research, a grey prediction model combined with a polynomial regression model was applied to calculate future carbon emissions from 2015-2020. Based on historical and predicted carbon emissions, we used the LMDI decomposition model to analyze the contributions of different factors to changing carbon emissions in Jiangsu. We aimed at discussing the future direction of emission reduction for Jiangsu and providing advice on the formulation of emission reduction policies not only for the province studied in this work, but for other provinces of similar socioeconomic backgrounds.

From the analysis we can conclude that:

(1) During the period of 2015-2020, the carbon emission of Jiangsu Province will increase at a constant pace.

(2) Rapid economic growth is the main driving force that results in increasing carbon emissions. Energy intensity is the key factor for reducing carbon emissions. The results are consistent with the conclusion of the literatures $[6,18,21]$.

(3) Changes in the level of population size and structure, as well as industrial and energy-consumption structures, will also affect carbon emissions.

(4) It is very likely that Jiangsu province will achieve a decrease of $40 \%-50 \%$ in $\mathrm{CO}_{2}$ emissions per unit of GDP in 2020 as compared to the 2005 target. According to the prediction results, the population will increase to 83.4 million in 2020 from 75.88 million in 2005; total GDP of the three industries (primary, secondary, tertiary) will be 17,274.7 billion yuan ( $\$ 2.6044$ trillion, USD); and carbon emissions will reach 130.4 million tons per year. Under such circumstances, the $\mathrm{CO}_{2}$ emissions per unit of GDP of the primary, secondary, and tertiary industry in 2020 will decrease by $55.11 \%, 42.96 \%$, and $75.2 \%$, respectively, as compared to 2005 .

\subsection{Suggestions}

According to the conclusions made, the following advice for Jiangsu province and other provinces with similar situations is put forward:

(1) The economic growth speed of Jiangsu will not undergo a significant decrease in the short term. Thus, it can be seen that with respect to Jiangsu, it is not enough to only rely on the control of economic growth for emission reduction; what is more important is to cooperate with other emission reduction related affairs.

(2) As energy intensity is the key factor for reducing carbon emissions, it is necessary for enterprises to improve energy utilization efficiency. In terms of the energy consumption structure of Jiangsu, enterprises should be encouraged to control the rate of raw coal consumption and total energy consumption, and promote the usage of natural gas or other clean energies. Furthermore, as the largest negative contribution of the energy intensity factor comes from the secondary industry, it is suggested that the adjustments and upgrades of the industrial structure should be adhered to and new environmental protection technologies should be used to transform existing industrial enterprises.

(3) As the transformation process of development centers changes to the tertiary industry, focus should be paid to the carbon emission of the tertiary industry, for there is a great need for energy in some parts of the tertiary industry, such as the catering and transportation industries. Therefore, the adjustment of the industrial structure should not only be focused on reducing the proportion off secondary industries, but the characteristics of the tertiary industry should also be considered.

(4) It is essential for each city to revise original policies to meet long-term emission reduction targets, and pay attention to the industry that can achieve low- or zero-emissions in all stages of their life cycles. 
Acknowledgments: This paper was sponsored by the Research Innovation Program for College Graduates of Jiangsu Province (Grant No. KYLX16_0924), the Opening Fund of Institute of Climate change and Public Policy, Nanjing University of Information Science and Technology, P. R. China (No. 14QA019) and the Seventh High-level Talents Project of the "Six Talent Peaks" Project in Jiangsu Province (S7410008001).

Author Contributions: All the authors contributed equally to this work. All authors read and approved the final manuscript.

Conflicts of Interest: The authors declare no conflict of interest.

\section{References}

1. Kais, S.; Sami, H. An econometric study of the impact of economic growth and energy use on carbon emissions: Panel data evidence from fifty eight countries. Renew. Sustain. Energy Rev. 2016, 59, 1101-1110. [CrossRef]

2. Kuznets, P.; Simon, P. Economic growth and income inequality. Am. Econ. Rev. 1955, 45, 1-28.

3. Lau, L.S.; Choong, C.K.; Eng, Y.K. Carbon dioxide emission, institutional quality, and economic growth: Empirical evidence in Malaysia. Renew. Energy 2014, 68, 276-281. [CrossRef]

4. Gallego-Álvarez, I.; Segura, L.; Martínez-Ferrero, J. Carbon emission reduction: The impact on the financial and operational performance of international companies. J. Clean. Prod. 2014, 103, 149-159. [CrossRef]

5. Burke, P.J.; Shahiduzzaman, M.; Stern, D.I. Carbon dioxide emissions in the short run: The rate and sources of economic growth matter. Glob. Environ. Chang. 2015, 33, 109-121. [CrossRef]

6. Tan, X.; Dong, L.; Chen, D.; Gu, B.; Zeng, Y. China's regional $\mathrm{CO}_{2}$, emissions reduction potential: A study of Chongqing city. Appl. Energy 2016, 162, 1345-1354. [CrossRef]

7. Ertugrul, H.M.; Cetin, M.; Seker, F.; Seker, F.; Dogan, E. The impact of trade openness on global carbon dioxide emissions: Evidence from the top ten emitters among developing countries. Ecol. Indic. 2016, 67, 543-555. [CrossRef]

8. Leong, C.C.; Blakey, S.; Wilson, C.W. Genetic Algorithm optimised Chemical Reactors network: A novel technique for alternative fuels emission prediction. Swarm Evol. Comput. 2015, 27, 180-187. [CrossRef]

9. Gardezi, S.S.S.; Shafiq, N.; Zawawi, N.A.W.A.; Khamidi, M.F.; Farhan, S.A. A multivariable regression tool for embodied carbon footprint prediction in housing habitat. Habitat Int. 2016, 53, 292-300. [CrossRef]

10. Pao, H.T.; Fu, H.C.; Tseng, C.L. Forecasting of $\mathrm{CO}_{2}$, emissions, energy consumption and economic growth in China using an improved grey model. Energy 2012, 40, 400-409. [CrossRef]

11. Deng, J.L. Control problems of Grey system. Syst. Contr. Lett. 1982, 1, 288-294.

12. Wang, J.; Jiang, H.; Zhou, Q.; Wu, J.; Qin, S. China's natural gas production and consumption analysis based on the multicycle Hubbert model and rolling Grey model. Renew. Sustain. Energy Rev. 2016, 53, 1149-1167. [CrossRef]

13. Chen, L.; Lin, W.; Li, J.; Tian, B.; Pan, H. Prediction of lithium-ion battery capacity with metabolic grey model. Energy 2016, 106, 662-672. [CrossRef]

14. Hamzacebi, $\mathrm{C}$; Karakurt, I. Forecasting the Energy-related $\mathrm{CO}_{2}$ Emissions of Turkey Using a Grey Prediction Model. Energy Sources Part A Recover. Util. Environ. Eff. 2015, 37, 1023-1031. [CrossRef]

15. Wang, X.; Cai, Y.; Xu, Y.; Zhao, H.; Chen, J. Optimal strategies for carbon reduction at dual levels in China based on a hybrid nonlinear grey-prediction and quota-allocation model. J. Clean. Prod. 2014, 83, 185-193. [CrossRef]

16. Ang, B.W.; Zhang, F.Q. A survey of index decomposition analysis in energy and environmental studies. Energy 2000, 25, 1149-1176. [CrossRef]

17. Ang, B.W. Decomposition analysis for policy making in energy: Which is the preferred method? Energy Policy 2004, 32, 1131-1139. [CrossRef]

18. Wang, Q.W.; Wang, Y.Z.; Zhou, P.; Wei, H.Y. Whole Process Decomposition of Energy-Related $\mathrm{SO}_{2}$ in Jiangsu Province, China. Appl. Energy 2016. Available online: http://www.sciencedirect.com/science/article/pii/ S0306261916306705 (accessed on 19 May 2016).

19. Ma, P.; Wang, L.S.; Guo, N. Modeling of hydronic radiant cooling of a thermally homeostatic building using a parametric cooling tower. Appl. Energy 2014, 127, 172-181. [CrossRef]

20. Wang, Q.W.; Hang, Y.; Zhou, P.; Wang, Y.Z. Decoupling and attribution analysis of industrial carbon emissions in Taiwan. Energy 2016, 113, 728-738. [CrossRef] 
21. Wang, Q.W.; Chiu, Y.H.; Chiu, C.R. Driving factors behind carbon dioxide emissions in China: A modified production-theoretical decomposition analysis. Energy Econ. 2015, 51, 252-260. [CrossRef]

22. Jiangsu Statistical Bureau. Jiangsu Statistical Year Book 2001; China Statistic Press: Beijing, China, 2001. (In Chinese)

23. Jiangsu Statistical Bureau. Jiangsu Statistical Year Book 2002; China Statistic Press: Beijing, China, 2002. (In Chinese)

24. Jiangsu Statistical Bureau. Jiangsu Statistical Year Book 2003; China Statistic Press: Beijing, China, 2003. (In Chinese)

25. Jiangsu Statistical Bureau. Jiangsu Statistical Year Book 2004; China Statistic Press: Beijing, China, 2004. (In Chinese)

26. Jiangsu Statistical Bureau. Jiangsu Statistical Year Book 2005; China Statistic Press: Beijing, China, 2005. (In Chinese)

27. Jiangsu Statistical Bureau. Jiangsu Statistical Year Book 2006; China Statistic Press: Beijing, China, 2006. (In Chinese)

28. Jiangsu Statistical Bureau. Jiangsu Statistical Year Book 2007; China Statistic Press: Beijing, China, 2007. (In Chinese)

29. Jiangsu Statistical Bureau. Jiangsu Statistical Year Book 2008; China Statistic Press: Beijing, China, 2008. (In Chinese)

30. Jiangsu Statistical Bureau. Jiangsu Statistical Year Book 2009; China Statistic Press: Beijing, China, 2009. (In Chinese)

31. Jiangsu Statistical Bureau. Jiangsu Statistical Year Book 2010; China Statistic Press: Beijing, China, 2010. (In Chinese)

32. Jiangsu Statistical Bureau. Jiangsu Statistical Year Book 2011; China Statistic Press: Beijing, China, 2011. (In Chinese)

33. Jiangsu Statistical Bureau. Jiangsu Statistical Year Book 2012; China Statistic Press: Beijing, China, 2012. (In Chinese)

34. Jiangsu Statistical Bureau. Jiangsu Statistical Year Book 2013; China Statistic Press: Beijing, China, 2013. (In Chinese)

35. Jiangsu Statistical Bureau. Jiangsu Statistical Year Book 2014; China Statistic Press: Beijing, China, 2014. (In Chinese)

36. Jiangsu Statistical Bureau. Jiangsu Statistical Year Book 2015; China Statistic Press: Beijing, China, 2015. (In Chinese)

37. State Statistical Bureau. China Energy Statistical Yearbook 2001; China Statistic Press: Beijing, China, 2001. (In Chinese)

38. State Statistical Bureau. China Energy Statistical Yearbook 2002; China Statistic Press: Beijing, China, 2002. (In Chinese)

39. State Statistical Bureau. China Energy Statistical Yearbook 2003; China Statistic Press: Beijing, China, 2003. (In Chinese)

40. State Statistical Bureau. China Energy Statistical Yearbook 2004; China Statistic Press: Beijing, China, 2004. (In Chinese)

41. State Statistical Bureau. China Energy Statistical Yearbook 2005; China Statistic Press: Beijing, China, 2005. (In Chinese)

42. State Statistical Bureau. China Energy Statistical Yearbook 2006; China Statistic Press: Beijing, China, 2006. (In Chinese)

43. State Statistical Bureau. China Energy Statistical Yearbook 2007; China Statistic Press: Beijing, China, 2007. (In Chinese)

44. State Statistical Bureau. China Energy Statistical Yearbook 2008; China Statistic Press: Beijing, China, 2008. (In Chinese)

45. State Statistical Bureau. China Energy Statistical Yearbook 2009; China Statistic Press: Beijing, China, 2009. (In Chinese)

46. State Statistical Bureau. China Energy Statistical Yearbook 2010; China Statistic Press: Beijing, China, 2010. (In Chinese) 
47. State Statistical Bureau. China Energy Statistical Yearbook 2011; China Statistic Press: Beijing, China, 2011. (In Chinese)

48. State Statistical Bureau. China Energy Statistical Yearbook 2012; China Statistic Press: Beijing, China, 2012. (In Chinese)

49. State Statistical Bureau. China Energy Statistical Yearbook 2013; China Statistic Press: Beijing, China, 2013. (In Chinese)

50. State Statistical Bureau. China Energy Statistical Yearbook 2014; China Statistic Press: Beijing, China, 2014. (In Chinese)

51. State Statistical Bureau. China Energy Statistical Yearbook 2015; China Statistic Press: Beijing, China, 2015. (In Chinese)

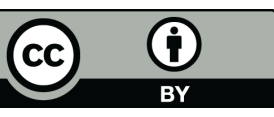

(C) 2016 by the authors; licensee MDPI, Basel, Switzerland. This article is an open access article distributed under the terms and conditions of the Creative Commons Attribution (CC-BY) license (http://creativecommons.org/licenses/by/4.0/). 